\title{
Caracterização do setor madeireiro de Rorainópolis, sul de Roraima
}

\author{
Bruno Roberto de Sousa Crivelli ${ }^{1}$, Jefferson Peixoto Gomes ${ }^{2 \star}$, Weslley Wilker Corrêa Morais ${ }^{1}$, Tiago \\ Monteiro Condét, ${ }^{1,3}$ Raylanne de Lima Santos ${ }^{1}$, Osmar Serra Bonfim Filho ${ }^{1}$ \\ ${ }^{1}$ Curso de Engenharia Florestal, Universidade Estadual de Roraima (UERR), São João da Baliza e Rorainópolis, Roraima, \\ Brasil. \\ ${ }^{2}$ Programa de pós-graduação em Ciências Florestais e Ambientais, Universidade Federal do Amazonas (UFAM), Manaus, \\ Amazonas, Brasil. \\ ${ }^{3}$ Programa de Pós-Graduação em Ciências de Florestas Tropicais, Instituto Nacional de Pesquisas da Amazônia (INPA), \\ Manaus, Amazonas, Brasil
}

\begin{abstract}
RESUMO Buscou-se realizar um diagnóstico do setor madeireiro de Rorainópolis (Roraima) visando gerar informações que subsidiem o desenvolvimento de políticas públicas voltadas para a gestão florestal no Estado. Foi aplicado um questionário em nove serrarias com o intuito de obter informações sobre localização atual e anterior, tempo de atuação; espécie, volume de madeira serrada e origem da matéria prima; o destino da madeira processada; o tipo de armazenamento e de secagem. As serrarias eram empreendimentos novos com no máximo 5 anos de atuação no município. Os empresários abordaram que as dificuldades são a burocratização do licenciamento ambiental e o alto custo das taxas de licenciamento. Dentre as espécies comerciais processadas pelas empresas entrevistadas destacam-se: Manilkara huberi $\left(9.860 \mathrm{~m}^{3}\right)$, Dinizia excelsa $\left(9.235 \mathrm{~m}^{3}\right)$, Hymenolobium excelsum $\left(4.440 \mathrm{~m}^{3}\right)$, Goupia glabra $\left(3.880 \mathrm{~m}^{3}\right)$, Erisma fuscum $\left(2.170 \mathrm{~m}^{3}\right)$, Qualea paraensis $\left(1.350 \mathrm{~m}^{3}\right)$, Protium sp. $\left(1.000 \mathrm{~m}^{3}\right)$, Clarisia racemosa $\left(1.000 \mathrm{~m}^{3}\right)$, Couratari stellata $\left(320 \mathrm{~m}^{3}\right)$, Bagassa guianensis $\left(280 \mathrm{~m}^{3}\right)$ e Handroanthus sp. $(77$ $\mathrm{m}^{3}$ ). A principal fonte de obtenção de matéria-prima foram os projetos de corte raso em propriedades rurais do sul do Estado. Os estados brasileiros aos quais foi destinada a maior parte da madeira processada de Rorainópolis foram Bahia, Ceará, Goiás e Amazonas, e observou-se a Venezuela como destino internacional mais relevante. Para secagem da madeira, quando realizada, o método utilizado é ao ar livre. Recomenda-se que é necessário criar mecanismos para desestimular a extração seletiva e predatória de madeira, legal ou ilegal, desenvolver meios para incentivar a prática do manejo florestal sustentável.
\end{abstract}

Palavras-chave: Amazônia; espécies madeireiras; rendimento; serraria.

\section{Characterization of the timber sector of Rorainópolis, south of Roraima}

\begin{abstract}
A diagnosis was made of the timber sector of Rorainópolis (Roraima) aiming to generate information that would support the development of public policies aimed at forest management in the State. The questionnaire was applied to nine sawmills in order to obtain information about current and previous location, time of operation; species, lumber volume and origin of the raw material; the destination of processed wood; the type of storage and drying. The sawmills were new enterprises with a maximum of 5 years of operation in the municipality. The businessmen said that the difficulties are the bureaucratization of environmental licensing and the high cost of licensing fees. The main commercial species processed by the companies interviewed were: Manilkara huberi $\left(9.860 \mathrm{~m}^{3}\right)$, Dinizia excelsa $\left(9.235 \mathrm{~m}^{3}\right)$, Hymenolobium excelsum $\left(4.440 \mathrm{~m}^{3}\right)$, Goupia glabra $\left(3.880 \mathrm{~m}^{3}\right)$, Erisma fuscum $\left(2.170 \mathrm{~m}^{3}\right)$, Qualea paraensis $\left(1.350 \mathrm{~m}^{3}\right)$, Protium sp. $\left(1.000 \mathrm{~m}^{3}\right)$, Clarisia racemosa $\left(1.000 \mathrm{~m}^{3}\right)$, Couratari stellata $\left(320 \mathrm{~m}^{3}\right)$, Bagassa guianensis $\left(280 \mathrm{~m}^{3}\right)$ e Handroanthus $s p .\left(77 \mathrm{~m}^{3}\right)$. The main source of getting raw materials were clearcut projects in rural properties in the south of the state. The main Brazilian states who buy the processed wood of Rorainópolis were Bahia, Ceará, Goiás and Amazonas, and has Venezuela as its main importer of wood. When wood is dried, the method is used outdoors. It is recommended that mechanisms should be created to reject a selective and predatory extraction of timber, legal or illegal, to develop means to encourage a sustainable forest management practice.
\end{abstract}

Keywords: Amazon; timber species; sawmill; yield; sawmill. 


\section{Introdução}

O declínio dos estoques de madeira tropical nos países asiáticos, principais fornecedores mundiais, contribuiu fortemente para que as atenções se voltassem para a floresta Amazônica (HIGUCHI et al., 2007; HIGUCHI, 2016), com maior porção territorial alocada no Brasil. Isto se deve ao fato da floresta Amazônica, apresentar um enorme potencial para o suprimento de matéria-prima para as indústrias florestais, principalmente o de madeira tropical. No entanto, este é um potencial, além de esgotável quando utilizado inadequadamente, ainda pode ser reduzido pelo desperdício de madeira, tanto no momento da exploração quanto no processamento nas indústrias madeireiras.

Segundo Pereira et al. (2010), o aproveitamento médio das serrarias nos estados Amazônicos é de 41,1\%. O estado do Acre apresentou o maior rendimento (45,7\%) no processamento desta matéria-prima, seguido por Mato Grosso (44,8\%) e Amapá (43,6\%). Roraima (37,2\%) e Maranhão $(35,4 \%)$ foram os estados amazônicos com o pior aproveitamento da tora. Danielli et al. (2016), avaliando o rendimento de madeira serrada para a maçaranduba (Manilkara spp.) no estado de Roraima, obtiveram um valor de $30,1 \%$. As taxas de rendimento das serrarias na Amazônia, de modo geral, estão associadas ao baixo capital de investimento e à falta de manejo adequado. Resultando em alta geração de resíduos, na maioria das vezes incinerados, que leva a grandes impactos ambientais (DIAS et al., 2015).

A principal fonte de matéria prima do setor madeireiro em Roraima são os projetos de corte raso em pequenas propriedades rurais, nos quais o manejo florestal sustentado é praticamente incipiente (GIMENEZ et al., 2015). Isto representa um risco para a sustentabilidade deste setor a médio e longo prazo, pois com o esgotamento do estoque de madeira nas áreas propicias ao corte raso também reduzirá a oferta de matéria-prima para as serrarias. Neste caso, a prática do manejo florestal sustentável poderá contribuir tanto para a manutenção do abastecimento do setor madeireiro quanto a cobertura florestal.

O Estado tem recebido uma grande quantidade de migrantes de outras unidades da federação, atraídos pela perspectiva de fácil acesso à terra e incentivo financeiro para os serviços agropecuários (BARNI et al., 2012; 2016). Esses dois fatores têm provocado sérios problemas ambientais, uma vez que estimulam a prática do desmatamento como forma de beneficiamento da propriedade e, consequentemente, ao acesso do título definitivo e ao crédito agropecuário. Roraima não dispõe ainda, de uma política de desenvolvimento sustentável consolidada e de ordenamento do setor florestal, porém o setor madeireiro possui um relevante papel na participação das exportações do Estado (SILVA; SILVA, 2008; DIAS et al., 2015).

A realização deste trabalho justifica-se pela necessidade de se obter informações sobre o setor madeireiro do município de Rorainópolis-RR. O conhecimento sobre este setor como a localização atual e anterior, tempo de atuação, suas relações com a origem da matéria-prima, volume desdobrado anualmente por espécie, rendimento, destino da madeira processada, o tipo de armazenamento, secagem e a destinação dos resíduos gerados contribuirá para disciplinar o aproveitamento dos recursos florestais, facilitar o entendimento do potencial produtivo e funcionamento do setor e para o fortalecimento da política florestal no Estado. Diante do exposto, o objetivo do presente trabalho foi caracterizar o setor madeireiro de Rorainópolis-RR, levantando informações sobre as espécies comerciais madeireiras utilizadas pelas serrarias locais e o principal destino da madeira processada. 


\section{Material e Métodos}

O município de Rorainópolis-RR possui 24.279 habitantes, com uma área total de $33.594,046 \mathrm{~km}^{2}$ (IBGE, 2014). Está localizado no sul de Roraima, no eixo da rodovia BR-174, nas coordenadas geográficas $60^{\circ} 25^{\prime} 47^{\prime \prime}$ de longitude Oeste e $00^{\circ}$
56'46" de latitude Norte (Figura 1). O clima é tropical quente, a temperatura média anual é de $26^{\circ} \mathrm{C}$ e apresenta uma cobertura vegetal caracterizada por uma Floresta Ombrófila Densa, com predomínio de árvores emergentes de grande porte (SE-

PLAN, 2010).
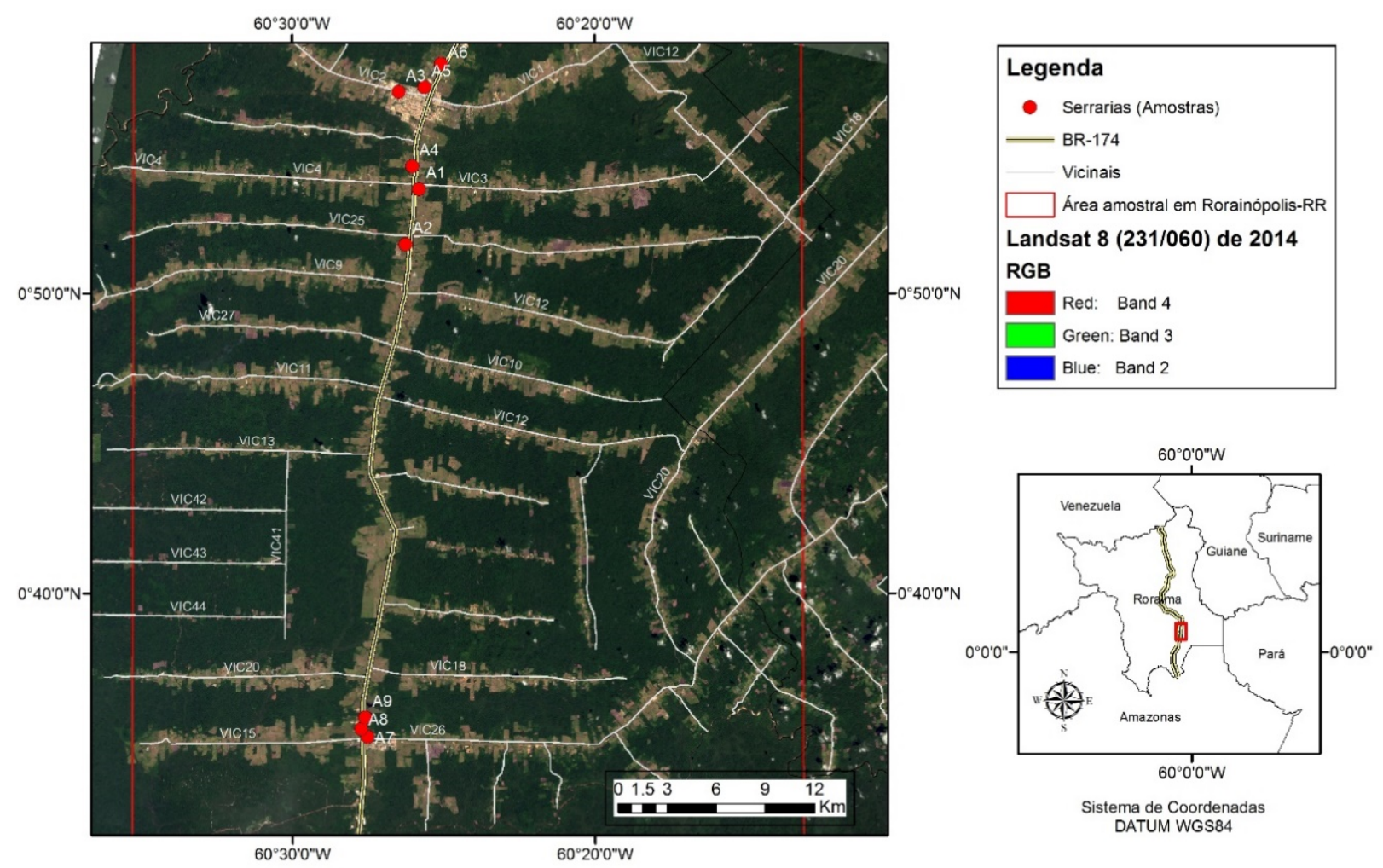

Figura 1. Mapa de localização do Município de Rorainópolis, sul de Roraima.

Figure 1. Location of the city of Rorainópolis, south of Roraima.

Para a realização do presente trabalho foi aplicado um questionário em nove serrarias (38\%) do setor madeireiro de Rorainópolis, selecionadas aleatoriamente, nas proximidades da BR-174, no período de março a maio de 2013. Este questionário procurou obter as seguintes informações: tempo de atuação da empresa no setor madeireiro em Rorainópolis-RR; localização atual (para facilitar o retorno à empresa para esclarecimento de dúvidas em relação aos dados coletados); localização anterior (para saber a origem inicial da empresa); origem e espécie da matéria prima; volume desdobrado por espécie; destino da madeira processada; tipo de armazenamento na serraria; e o tipo de secagem. Visando o sigilo, as empresas foram denominadas em serrarias 1 a 9 .

\section{Resultados e Discussão}

No ano de 2013 haviam 53 serrarias cadastradas no setor tributário da prefeitura de Rorainópolis-RR. No estudo realizado por Pereira et al. (2010), foram encontradas apenas 37 
serrarias ativas no polo madeireiro do Estado. Entretanto, de acordo com a Fundação Estadual de Recursos Hídricos - FEMARH, apenas 24 serrarias deram entrada ao processo de licenciamento ambiental para o desdobramento de madeira em Rorainópolis, no período de 2004 a 2013, sendo que o abastecimento e a distribuição de energia elétrica de Rorainópolis-RR são os principais fatores limitantes para as indústrias se instalarem no Município, que tem a madeira processada como um dos principais produtos exportados.

O tempo médio de atuação das empresas entrevistadas foi de 2,9 $\pm 2,1$ anos, sendo todas originárias Rorainópolis-RR. Cunha et al. (2009), encontraram resultado distinto a este trabalho ao avaliar o tempo de atividades de 20 empresas em distintos setores madeireiros de Roraima, constatando uma média de 7 anos de atividade, com um período máximo de 16 anos. Este fato pode ser explicado devido as empresas, geralmente, migrarem em busca da proximidade das fontes da madeira, facilidade de acesso, com intuito de reduzir os custos de transporte e extração florestal (SILVA; SILVA, 2008). Cabe salientar, que o setor madeireiro no estado de Roraima é considerado intermediário (10-30 anos), se comparado com outros polos ou fronteiras madeireiros antigas na Amazônia, como Sinop e Feliz Natal (MT) e Paragominas e Tailândia (PA), com mais de 30 anos (PEREIRA et al., 2010).

Quanto à regularização ambiental das empresas entrevistadas, foi constatado que apenas $33,3 \%$ das serrarias entrevistadas haviam entrado com o pedido de Licenciamento Ambiental junto ao órgão ambiental do Estado, a Fundação Estadual do Meio Ambiente e Recursos Hídricos (FEMARH). Os empresários que ainda não haviam iniciado o processo de Licenciamento Ambiental afirmaram que o principal motivo é a burocratização do licenciamento ambiental, pelos órgãos ambientais, aliado ao alto custo das taxas de licenciamento e vistoria. Além destes, a precária infraestrutura para escoa- mento da produção e a questão fundiária problemática do Estado são fatores que podem ter contribuído para algumas empresas trabalharem na ilegalidade. Corroborando com Lima et al. (2005) e Tonini; Lopes (2006), ao afirmarem que as principais dificuldades para a obtenção de madeira legalizada é o alto custo para elaboração dos planos de manejo florestal e a morosidade dos órgãos ambientais competentes para emissão dos licenciamentos e autorização para a exploração. A pouca fiscalização sobre a extração ilegal de madeira também contribui para a competição desleal com a madeira de origem legal (ALMEIDA et al., 2010; ANGELO et al., 2014).

Conforme Cunha et al. (2009), vários países exigem a certificação florestal da madeira e que as empresas estejam em conformidade com a legislação ambiental para a importação. No estado de Roraima a certificação florestal é incipiente, sendo exploradas áreas de florestas naturais com apenas remanejo florestal e reposição florestal, na maioria das vezes com espécies exóticas (Acacia spp.), tendo pouco controle sobre a cadeia de custódia do recurso natural. Desta forma, uma alternativa para as empresas madeireiras seria contratar empresas especializadas em reposição florestal com essências nativas da mesma bacia hidrográfica ou fazer a compensação florestal.

A Figura 2 apresenta os volumes de madeira desdobrada por empresa. Foi possível observar que apenas três empresas foram responsáveis por $68 \%$ do total do volume de madeira processada nas serrarias estudadas. Enquanto que as outras 6 serrarias somam os $32 \%$ restantes da produção de madeira processada.

Analisando o volume de madeira desdobrada $\mathrm{em}^{3}$, obteve-se um valor médio de $1.636,9 \pm 1.415,4 \mathrm{~m}^{3}$ de madeira processada por mês nas serrarias em Rorainópolis - RR. As principais espécies processadas no setor madeireiro de Rorainópolis foram Angelim-ferro (Dinizia excelsa Ducke), Maçaranduba (Manilkara huberi (Ducke) A. Chev.), Cupiúba 
(Goupia glabra Aubl.), Angelim-pedra (Hymenolobium excelsum Ducke), Caferana (Erisma fuscum Ducke), Tatajuba (Bagassa guianensis Aubl.), Rabo-de-arraia (Qualea paraensis
Ducke), Casca-grossa (Protium sp.), Guariúba (Clarisia racemosa Ruiz), Ipê (Handroanthus sp.) e Tauari (Couratari stellata A.C. Sm.), totalizando 11 espécies madeireiras (Figura 3).

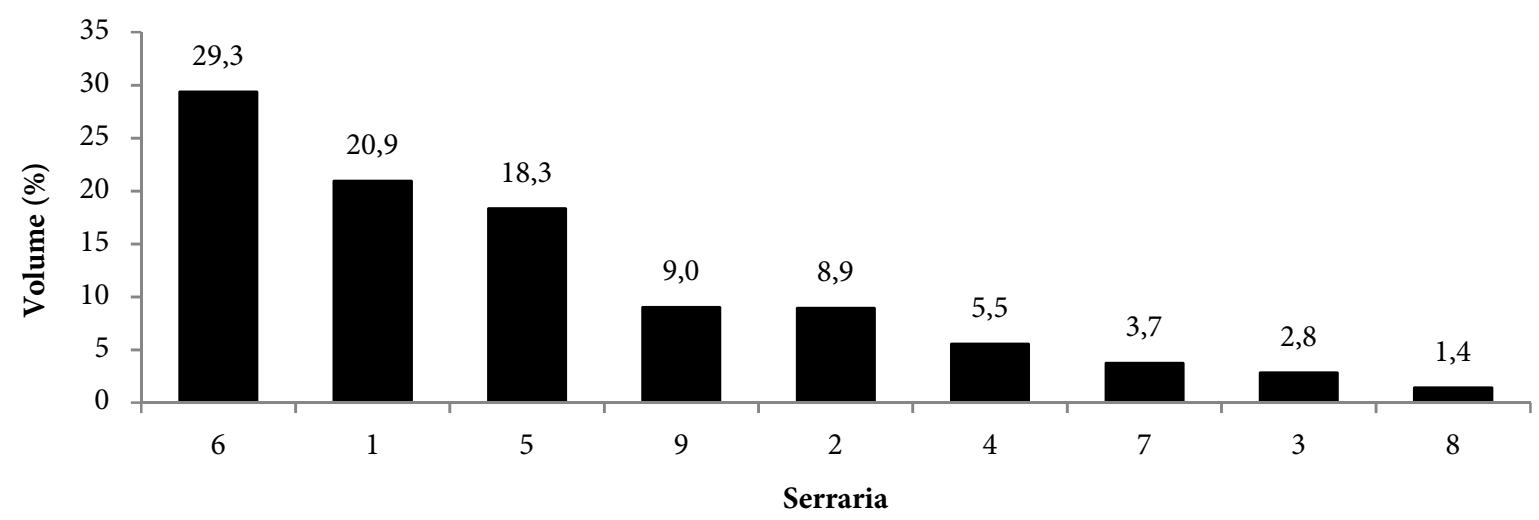

Figura 2. Comparativo entre os volumes de madeira desdobrada por serraria no município de Rorainópolis.

Figure 2. Comparison between the volume of sawn timber by sawmill in the city of Rorainópolis.

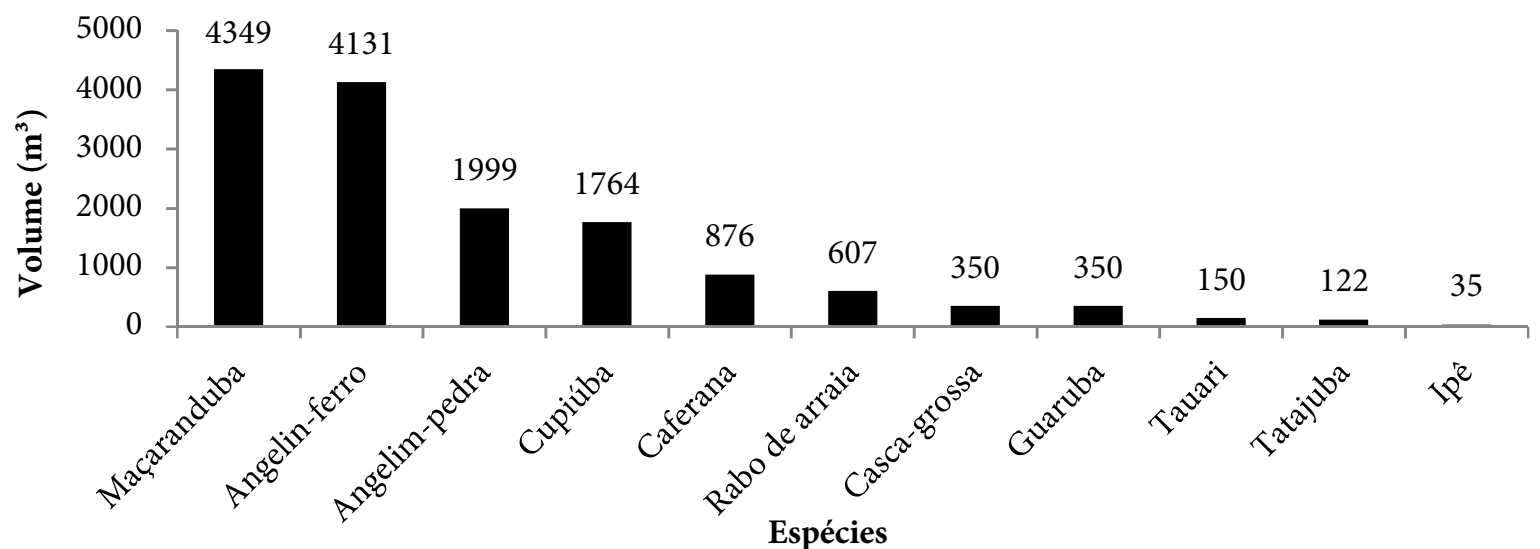

Figura 3. Volumetria das espécies processadas pelas empresas madeireiras amostradas no município de Rorainópolis, sul de Roraima.

Figure 3. Volumetric species processed by the timber companies shown in the municipality of Rorainópolis, south Roraima.

O alto valor comercial negociável e a grande demanda pelas espécies Maçaranduba, Angelim-ferro, Angelim-pedra e Cupiúba podem ter contribuído para estas espécies terem apresentado o maior volume de madeira processada dentre as empresas madeireiras entrevistadas. Outro fator determinante é a facilidade de se encontrar indíviduos destas espécies com diâmetro propicío ao corte, ou seja, Diâmetro a altura do Peito acima de $50 \mathrm{~cm}$, na região sul do estado de Roraima. Como demonstra o estudo realizado por Condé e Tonini (2013), no município de Caracaraí, constatando que a
Maçaranduba foi a espécie com potêncial madeireiro que apresentou o maior valor de importância.

Conforme Condé; Tonini (2013), em termos de manejo florestal sustentado para a produção de madeira, é de suma importância considerar as diferenças regionais na fitofisionomia das florestas, na autoecologia das espécies e no contexto socioeconômico em que a atividade é praticada em áreas ainda pouco estudadas como o estado de Roraima. A extração seletiva intensa de espécies florestais pode provocar 
futuramente a exaustão de madeira comercial em certas regiões.

O presente estudo apresenta resultado semelhante ao realizado no ano de 1988, por Barbosa (1990), quando avaliou o mercado madeireiro da região sul do Estado, que concentrava toda a sua produção em apenas 8 espécies, tendo como as principais o Angelim-pedra, a Cupiúba e a Caferana, representando 97,4\% da madeira processada. Assemelhando também ao trabalho realizado por Cunha et al. (2009), ao avaliar o comércio madeireiro em Roraima, constatou que as espécies mais comercializadas foram a Maçaranduba, Jatobá e Ipê. No entanto, conforme estes mesmos autores as espécies Angelim-ferro, Caferana e Cupiúba foram comercializadas por $70 \%$ das empresas entrevistadas no ano de 2009.

Em relação ao volume de madeira desdobrada por espécie a Maçaranduba destacou-se por apresentar $4.349 \mathrm{~m}^{3}$ de madeira serrada, seguida das espécies Angelim-ferro (4131 $\left.\mathrm{m}^{3}\right)$, Angelim-pedra $\left(1999 \mathrm{~m}^{3}\right)$ e Cupiúba $\left(1764 \mathrm{~m}^{3}\right)$. Estas quatro espécies representaram $83 \%$ de toda madeira processadas pelas empresas entrevistadas, sendo que deste total a espécie Maçaranduba representou aproximadamente 30\%. Cunha et al. (2009) também relata a superioridade da Maçaranduba, com $60 \%$ da madeira exportada de Roraima. Em 2013 foi realizado um estudo para estimar o rendimento no desdobro da maçaranduba (Manilkara huberi) pelas serrarias do estado de Roraima, constatando um rendimento de 30,1\% (DANIELLI et al., 2016). Desta forma, esta espécie merece destaque pela grande importância no setor madeireiro estadual, sendo necessário a realização de estudos que viabilizem sua extração como matéria-prima e que incentivem as empresas madeiras a trabalharem de forma sustentável e com maior rendimento.

O Ipê é uma espécie que vem substituindo o Mogno no mercado nacional e internacional, por produzir uma excelente madeira, com boas propriedades mecânicas, físicas e com boa trabalhabilidade (ALMEIDA et al., 2010). No entando esta é uma das espécies que apresentou um menor volume de madeira desdobrada, com $35 \mathrm{~m}^{3}$, representando apenas $0,2 \%$ do total da madeira serrada nas empresas entrevistadas. Este fato, pode estar relacionado a baixa distribução natural desta espécie ou devido a superexploração em tempos remotos nas florestas do sul de Roraima, sendo considerada mais frequente em florestas que abastecem o setor madeireiro de Boa Vista (BARBOSA, 1990; CUNHA et al., 2009).

Ao observar a origem da matéria-prima por espécies relacionando com seus respectivos volumes em tora, os entrevistados relataram que $54 \%$ é proveniente de corte raso, $35 \%$ não souberam especificar a origem da madeira em tora e apenas $11 \%$ do volume total é oriundo de Plano de Manejo Florestal Sustentável (Tabela 1). Corroborando com Tonini e Lopes (2006) afirmam que, embora o setor madeireiro desempenhe um importante papel na econômia do estado de Roraima, a sua matéria-prima é obtida de forma insustentável (ASNER et al., 2005; GIMENEZ et al., 2015). Isto pode contribuir com o processo de escassez de madeira das espécies mais utilizadas na região.

A matéria-prima oriunda de desmatamentos, autorizados ou não, é a forma de mais fácil acesso e de menor preço, assim estimulando as empresas madeireiras a adquirirem madeira de corte raso ao invés da madeira proveniente de plano de manejo sustentável. Alguns autores acreditam que aliado a este fato, existe a ineficiência dos instrumentos de controle e fiscalização ambiental para detectar a atividade ilegal, o que favorece a extração predatória de madeira, diminuindo a competitividade dos produtos de planos de manejo florestal sustentável (ASNER et al., 2005; LIMA et al., 2005). 
Tabela 1. Origem da matéria-prima, por espécie, para o abastecimento das serrarias do município de Rorainópolis - RR.

Table 1. Origin of the raw material, by specie, for supplying of the sawmills in the city of Rorainópolis - RR.

\begin{tabular}{|c|c|c|c|c|}
\hline Espécies & $\begin{array}{c}\text { Corte Raso } \\
\qquad\left(\mathbf{m}^{3}\right)\end{array}$ & $\begin{array}{l}\text { Não souberam especificar } \\
\qquad\left(\mathbf{m}^{3}\right)\end{array}$ & $\begin{array}{c}\text { PMFS } \\
\left(\mathbf{m}^{3}\right)\end{array}$ & $\begin{array}{l}\text { Total } \\
\left(\mathrm{m}^{3}\right)\end{array}$ \\
\hline Maçaranduba & 5.130 & 4.330 & 400 & 9.860 \\
\hline Angelim-ferro & 5.385 & 3.600 & 250 & 9.235 \\
\hline Angelim-pedra & 4.440 & - & - & 4.440 \\
\hline Cupiúba & 1.180 & 2.700 & - & 3.880 \\
\hline Caferana & 1.170 & - & 1.000 & 2.170 \\
\hline Rabo-de-arraia & 750 & 600 & - & 1.350 \\
\hline Casca-grossa & - & - & 1.000 & 1.000 \\
\hline Guaruba & - & - & 1.000 & 1.000 \\
\hline Tauari & - & 320 & - & 320 \\
\hline Tatajuba & 80 & 200 & - & 280 \\
\hline Ipê & - & - & 77 & 77 \\
\hline Total & 18.135 & 11.750 & 3.727 & 33.612 \\
\hline$\%$ & 54 & 35 & 11 & 100 \\
\hline
\end{tabular}

Diante disto, Barni et al. (2012), ao estudarem o comportamento do desmatamento no sul do estado de Roraima, constataram que o maior desmatamento ocorreu na área da BR-210 pela presença de grandes proprietários e invasões de terras. Já na BR-174, o desmatamento pode ter sido influenciado pelo crescimento do setor madeireiro de Rorainópolis, situado à margem desta Rodovia.

Conforme a Figura 4, os estados que mais importam a madeira processada no setor madeireiro de Rorainópolis são Bahia, Ceará e Goiás. Estes estados compram madeira de aproximadamente $67 \%$ das serrarias, e o único país a importar madeira das empresas amostradas é a Venezuela, de apenas uma serraria.

No ano de 2009, $88 \%$ das madeiras desdobradas por 20 serrarias tiveram como destino a Venezuela, enquanto que no ano de 2012 os principais países importadores de madeira serrada do estado de Roraima foram Venezuela e Holanda, correspondendo a $71 \%$ e $28 \%$, respectivamente, do total de madeira destinada à exportação (CUNHA et al., 2009).

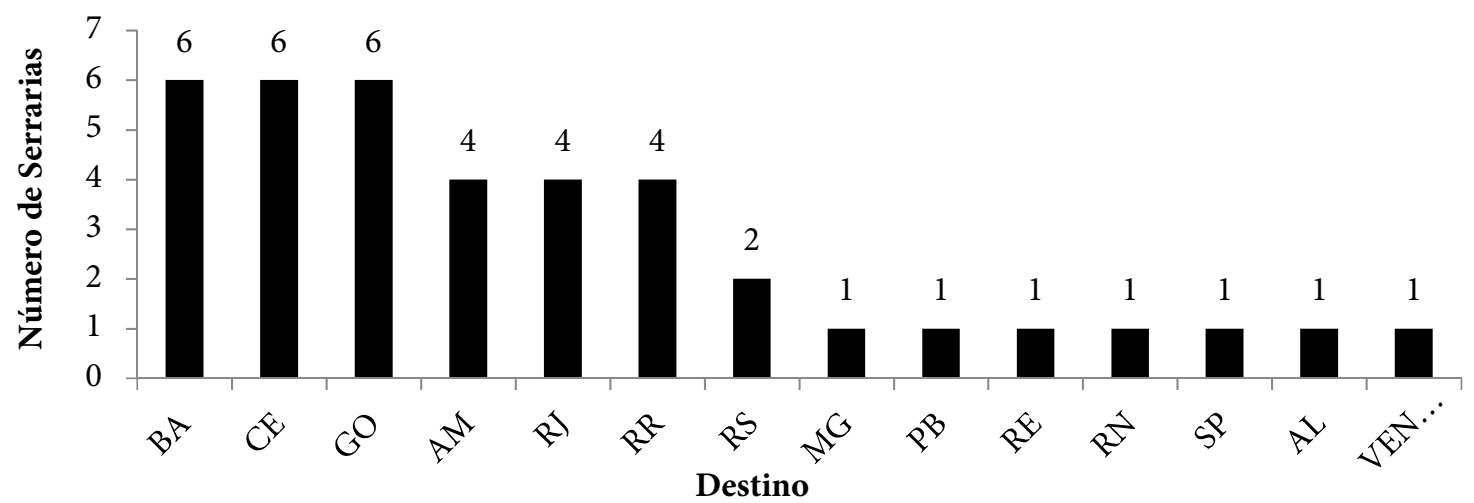

Figura 4. Destino da madeira processada nas serrarias do setor madeireiro de Rorainópolis, sul de Roraima.

Figure 4. Destination of wood processed in timber sector of Rorainópolis, south Roraima. 
Alguns autores afirmam que no ano de 2009 ocorreu um grande entrave na exportação de madeira para a Venezuela, devido à morosidade no processo de exportação de madeira (GARCIA et al., 2010). Conforme estes mesmos autores, esta demora teve como principal motivo problemas com a emissão da guia de mobilização florestal, por parte das autoridades venezuelanas, devido à burocratização demasiada. Esta guia é necessária para atestar a procedência e o tratamento sanitário do produto.

A secagem da madeira é umas fases primordiais para a transformação da madeira em produto acabado com maior qualidade (ELEOTÉRIO; SILVA, 2012), pelo fato de proporcionar melhor trabalhabilidade, redução da movimentação dimensional, redução ao ataque por fungos e insetos (SILVEIRA et al., 2013). No entanto ao aplicar o questionário foi constatado que a maioria das serrarias armazena a madeira processada ao ar livre, visando reduzir a umidade. Já em algumas serrarias as pilhas de madeira foram amontoadas diretamente dentro de contêineres, devido à urgência para a entrega da madeira serrada ao local de destino.

Se toda a madeira produzida no setor madeireiro de Rorainópolis passasse pelo processo de secagem poderia haver menor custo com transporte da madeira processada e as empresas teriam um produto de melhor qualidade, podendo assim ganhar na competitividade no mercado madeireiro. Porém, é necessário a realização de um trabalho para realizar o agrupamento das espécies processadas visando ordenar o processo de secagem considerando a densidade e o teor de umidade de cada espécie, conforme recomendado por Silveira et al. (2013). Isto devido as principais espécies processadas no setor madeireiro de Rorainópolis possuírem uma grande variabilidade, apresentando uma densidade que pode variar de $0,500 \mathrm{~g} . \mathrm{cm}^{3}$ (Couratari stellata) a $0,878 \mathrm{~g} . \mathrm{cm}^{3}(\mathrm{Ma}$ nilkara huberi).

\section{Conclusões}

Os empreendimentos foram considerados novos e originários do próprio município, ou seja, não foram provenientes de migração de outros municípios.

Apenas 33,3\% das serrarias haviam entrado com o pedido de Licenciamento Ambiental junto ao órgão ambiental do Estado.

As três principais espécies processadas pelas empresas entrevistadas foram Manilkara huberi $\left(9.860 \mathrm{~m}^{3}\right)$, Dinizia excelsa $\left(9.235 \mathrm{~m}^{3}\right)$, Hymenolobium excelsum $\left(4.440 \mathrm{~m}^{3}\right)$ totalizando $23.535 \mathrm{~m}^{3}$.

A principal fonte de obtenção de matéria-prima foram os projetos de corte raso em propriedades rurais do sul do Estado.

A maior parte da madeira processada em Rorainópolis teve como destino: Bahia, Ceará, Goiás e Amazonas, e observou-se que a Venezuela foi o único destino internacional relevante.

Quando realizada a secagem da madeira desdobrada, o método utilizado é ao ar livre.

\section{Referências}

ALMEIDA, A.N.; ANGELO, H.; SILVA, J.C.G.L. da; HOEFLICH, A. Mercado de madeiras tropicais: substituição na demanda de exportação. Revista Acta Amazonica, v. 40, n. 1, p. $119-126,2010$.

ANGELO, H.; SILVA, J.C.; ALMEIDA, A.N. de; POMPERMAYER, R. de S. Análise estratégica do manejo florestal na Amazônia brasileira. Revista Floresta, v. 44, n. 3, p. 341 - 348, 2014.

ASNER, G.P.; KNAPP, D.E.; BROADBENT, E.N.; OLIVEIRA, P.J.C.; KELLER, M.; SILVA, J.N.M. Selective Logging in the Brazilian Amazon. Journal Science, v. 310, p. 480-482, 2005. 
BARBOSA, R.I. Análise do setor madeireiro do estado de Roraima. Revista Acta Amazônica, v. 20, p. 193-209, 1990.

BARNI, P.E.; FEARNSIDE P.M.; GRAÇA P.M.L.A. Desmatamento no sul do estado de Roraima: padrões de distribuição em função de projetos de assentamento do INCRA e da distância das principais rodovias (BR-174 e BR-210). Revista Acta Amazonica, v. 42, n. 2, p. 195-204, 2012.

BARNI, P.E.; MANZI, A.O.; CONDÉ, T.M.; BARBOSA, R.I.; FEARNSIDE, P.M. Spatial distribution of forest biomass in Brazil's state of Roraima, northern Amazonia Forest Ecology and Management, v. 377, p. 170-181, 2016.

CONDÉ, T.M.; TONINI,H. Fitossociologia de uma Floresta Ombrófila Densa na Amazônia Setentrional, Roraima, Brasil. Revista Acta Amazonica, v. 43, n. 3, p. 247-260, 2013.

CUNHA, P.S.C.; SOUZA, R.B.L.; SOUZA, P.L. Análise do setor madeireiro de Roraima e sua integração com a contabilidade e o desenvolvimento sustentável. Revista Contexto, v. 9, n. 15, 2009.

DANIELLI, F.E.; GIMENEZ, B.O.; OLIVEIRA, C.K.A.; SANTOS, J. dos; HIGUCHI, N. Modelagem do rendimento no desdobro de toras de Manilkara spp. (Sapotaceae) em serraria do estado de Roraima, Brasil. Revista Scientia Forestalis, v. 44, n. 111, 2016.

DIAS, J.A.; SANTOS, C. M. L.; CONDÉ, T.M. A contabilidade ambiental no aproveitamento de resíduos madeireiros em Rorainópolis-RR. Revista Remgads, v. 8, p. 17-22, 2015.

ELEOTÉRIO, J.R.; SILVA, C.M.K. da. Comparação de programas de secagem para Cumaru (Dipteryx odorata), Jatobá (Hymenaea spp) e Muiracatiara (Astronium lecointei) obtidos por diferentes métodos. Revista Scientia Forestalis, v. 40, n. 96, p. 537-545, 2012.

SILVEIRA, L.H.C.; REZENDE, A.V.; VALE, A.T. Teor de umidade e densidade básica da madeira de nove espécies comerciais amazônicas. Revista Acta Amazonica, v. 43, n. 2, p. 179 - 184, 2013.

GARCIA C.; GONZALO, I.; BRANDÃO, C.N. Análise do processo de exportação de madeira procedente do município de Boa Vista/RR, nacionalizada pela aduana ecológica de Santa Elena de Uairén - Venezuela no ano de 2009. In: REUNIÃO REGIONAL DA SBPC EM BOA VISTA, Boa Vista, Roraima, 2010.
GIMENEZ, B.O.; DANIELLI, F.E.; OLIVEIRA, C.K.A.; SANTOS, J.; HIGUCHI, N. Equações volumétricas para espécies comerciais madeireiras do sul do estado de Roraima. Revista Scientia Forestalis, v. 43, n. 106, p. 291-301, 2015.

HIGUCHI, N. O papel da floresta amazônica como mitigadora dos efeitos da mudança climática global pretérita. Revista opiniões. Disponível em: < http://florestal.revistaopinioes.com.br/ revista /detalhes/7-floresta-amazonica-r-mudancas-climaticas/>. Acesso em: 05 set. 2016.

HIGUCHI, N.; SANTOS, J.; TEIXEIRA, L.M.; LIMA, A.J.N. O mercado internacional de madeira está à beira do colapso. Associação Brasil-Japão de Pesquisas. Scientific Journal, p. 33-41, 2007.

IBGE. Disponível em: <http://cidades.ibge.gov.br>. Acesso em 04 set. 2014 .

LIMA, J.R.A.; SANTOS, J.; HIGUCHI, N. Situação das indústrias madeireiras do estado do Amazonas em 2000. Revista Acta Amazônica, v. 35, n. 2, 2005. 2005.

PEREIRA, D; SANTOS, D; VEDOVETO, M; GUIMARÃES, J; VERÍSSIMO, A. Fatos florestais da Amazônia. Belém: Imazon, 2010. $124 \mathrm{p}$.

SEPLAN/RR. Informações socioeconômicas do Município de Rorainópolis - RR 2010. Boa Vista-RR, 2010.

SILVA, N.C.; SILVA, G.F.N. da. Contribuição do setor madeireiro à balança comercial do estado de Roraima: contexto econômico e ambiental. Revista Acta Geográfica, n. 3, p. 85$91,2008$.

TONINI, H.; LOPES, C.E.V. Características do setor madeireiro do Estado de Roraima. Boa Vista: Embrapa, 2006. 25 p. 